\title{
A CASE OF RUPTURE OF FLEXOR TENDONS SECONDARY TO KIENBÖCK'S DISEASE
}

\author{
J. I. P. James, London, ENGLANd
}

From the Institute of Orthopaedics, Royal National Orthopaedic Hospital

Pathological rupture of the flexor tendons at the wrist is uncommon. Colles fractures probably account for most cases; displaced fragments may cause attrition, or secondary arthritis may lead to degenerative changes in the related tendons and tendon sheaths (McMaster 1932). The case reported here of an unusual cause of rupture may be of some interest. Case history-F. R., aged fifty years, a motor driver, attended the Hand Clinic at the Royal National Orthopaedic Hospital complaining of aching pain in front of the left wrist of nine years' duration. In the first place the hand and fingers became swollen for one day

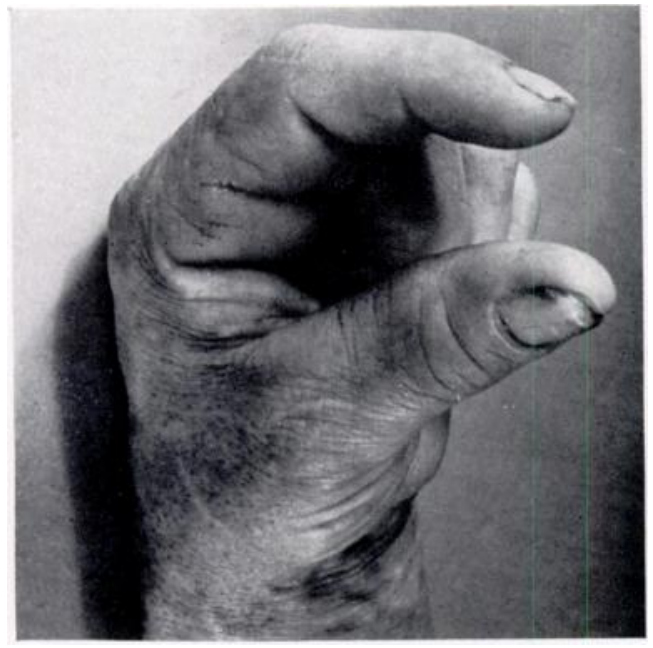

FIG. 1

Pre-operative photograph showing limitation of active flexion of the thumb and index finger.

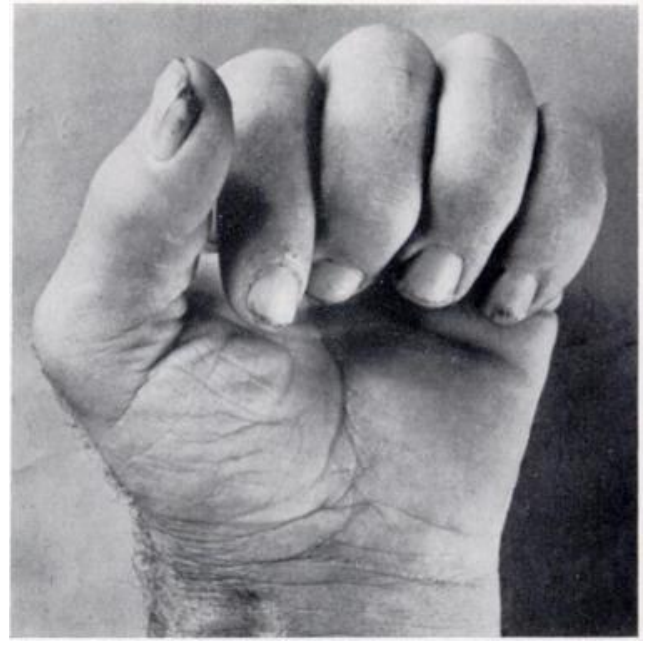

FIG. 2

To show the improvement in active flexion of the thumb and index finger six months after operation.

and he stayed away from work for two days; there was no history of injury. Four months before reporting he found that he was unable to flex the distal joint of the index finger. This loss of power happened for no apparent reason and without pain. Three months later, though he was not using his hand, it suddenly became cramped and assumed the obstetric position. There was severe pain, and when this and the cramp subsided he was unable to flex the interphalangeal joint of the thumb.

When he was examined one month later, a soft tissue swelling was visible in front of the wrist, and proximal to this, some hollowing of the radial half of the anterior surface of the forearm. He could not flex the distal joint of the thumb or of the index finger (Fig. 1). Dorsiflexion and radial abduction of the wrist joint were limited by approximately one-third. There was no loss of sensation in the hand and no wasting of the thenar muscles.

Radiographs of the wrist revealed longstanding Kienböck's disease of the semilunar bone which was dense and much compressed. In the lateral view several loose fragments could be seen in front of the proximal row of the carpus (Fig. 3).

Treatment-The flexor tendons were exposed at the wrist and the transverse carpal ligament was divided. The median nerve was normal. The tendons of flexor pollicis longus and flexor 

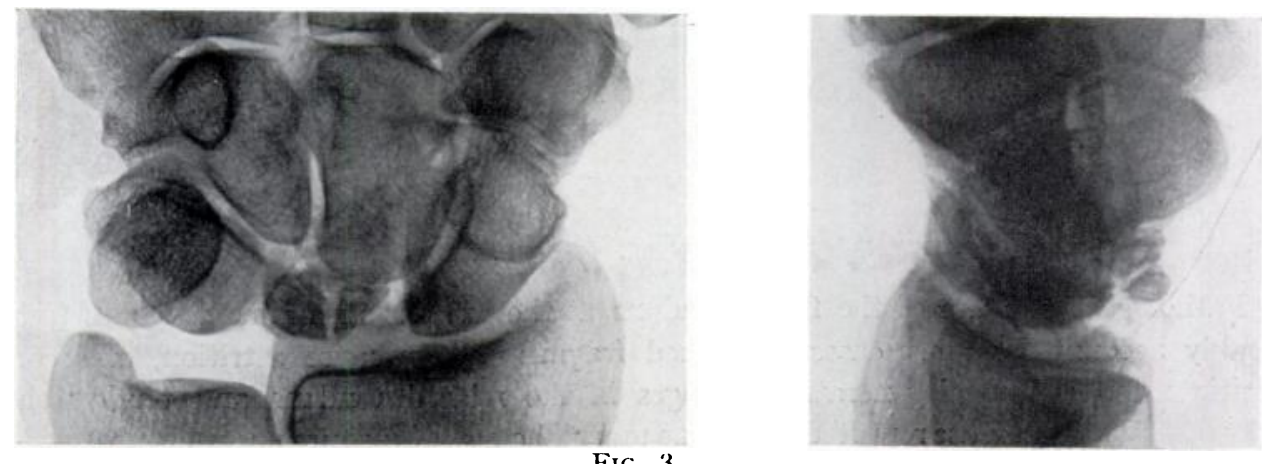

Radiographs of the wrist showing the dense fragmented semilunar bone.

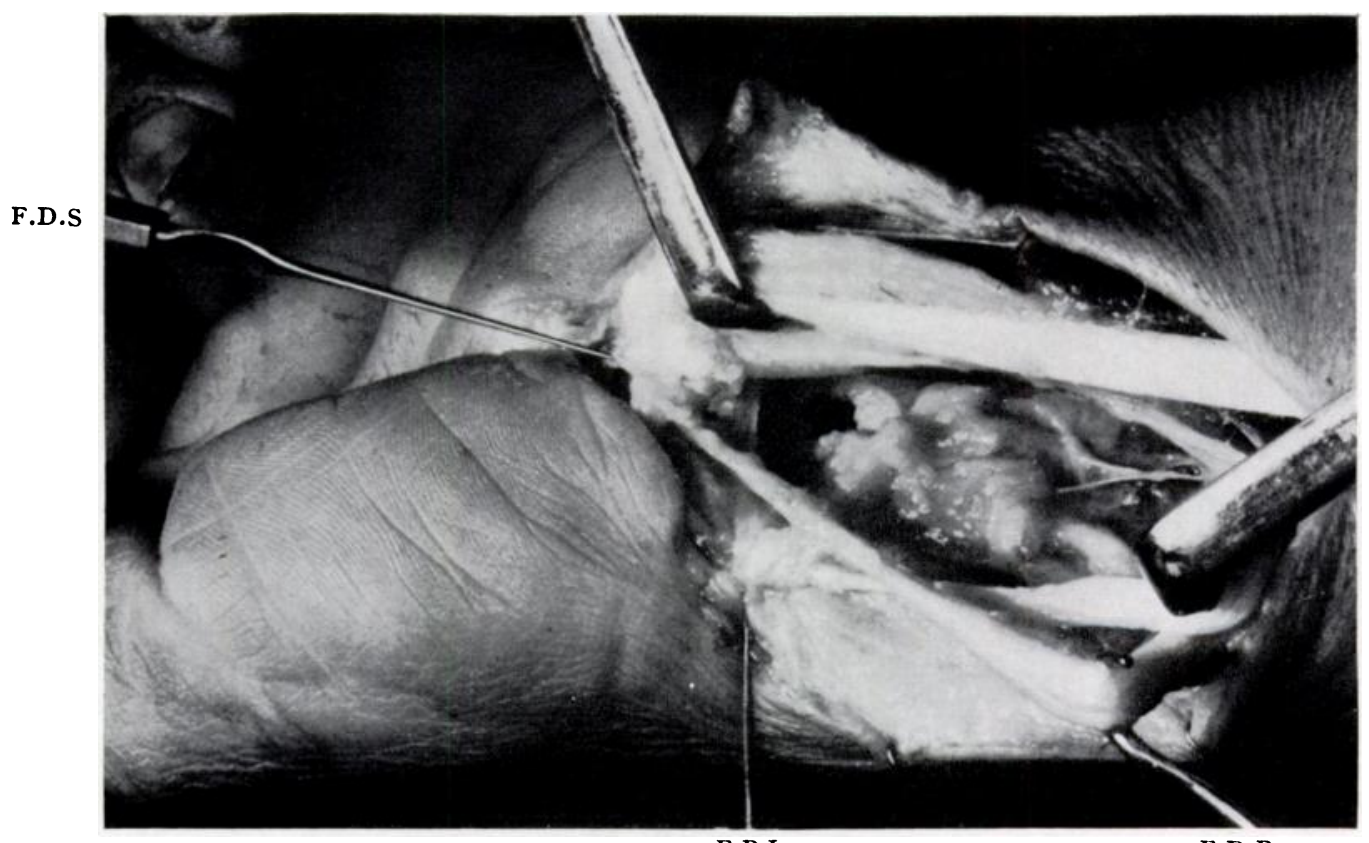

F.P.L.

F.D.P.

Fig. 4. Showing ruptured and frayed tendons. F.D.P.-flexor profundus to the index finger in continuity with its empty tendon sheath. F.P.L.-flexor pollicis longus similarly affected.

F.D.S.- - flexor sublimis to the index finger severely frayed. The aperture in the capsule can be seen in the angle between flexor profundus and flexor sublimis.

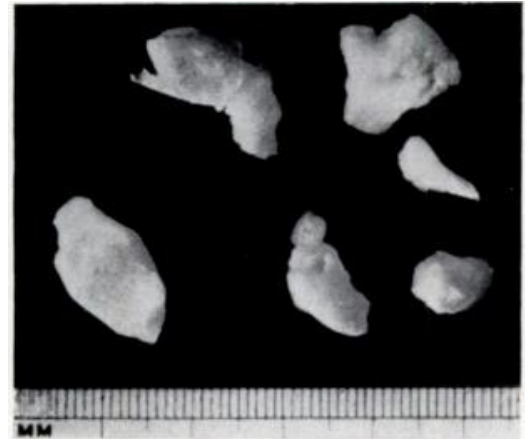

Fig. 5

The fragments of semilunar bone.

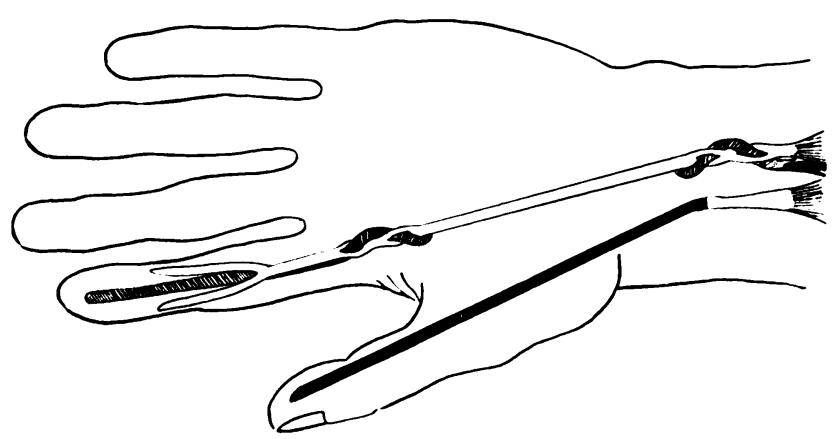

Fig. 6

The plan of the tendon repair.

THE JOURNAI, OF BONE AND JOINT SURGERY 
profundus to the index finger were found to be completely divided and separated by a gap of two and a half inches, across which ran the empty tendon sheaths (Fig. 4). The ends of each tendon had rounded off smoothly and there was no fraying. The adjacent tendons of flexor sublimis to the index and of flexor profundus to the middle finger were, however, grossly frayed like ropes worn half through. On exposure of the anterior capsule of the wrist an aperture was found leading to the affected semilunar; with flexion of the joint three small loose bodies were extruded (Fig. 5). The semilunar was excised, a dorsal incision being required for one mobile fragment.

Repair of the tendons was then effected (Fig. 6). The distal part of the tendon of flexor pollicis longus was resected. A long free graft from the extensor tendon of the third toe was then sutured in position by the Bunnell technique. The graft lay between the proximal end of the ruptured tendon and the insertion of flexor pollicis longus into the distal phalanx. Both proximal and distal ends of the profundus tendon to the index finger were sutured to the corresponding sublimis tendon with the finger in flexion. A plaster cast was applied with the thumb, index finger and wrist flexed and was retained for four weeks.

The post-operative recovery was uneventful. Six months after operation there were 10 degrees of active flexion of the distal joint of the index finger and the finger was no longer hyperextended when at rest. Active flexion of the interphalangeal joint of the thumb was strong through 15 degrees (Fig. 2). The patient found little disability in either digit and the wrist was painless.

Comment-The damaged flexor tendons are anatomically those most closely related to the semilunar. It is surmised that during flexion and extension of the wrist these tendons were pulled taut across the displaced fragments. No similar case has been discovered in an extensive search of the literature.

\section{REFERENCES}

Bunnell, Sterling (1948): Surgery of the Hand. Second edition. Philadelphia, London, Montreal: J. B. Lippincott Company.

Delarue, J., and Denoix, P. (1946): L'altération dégénérative des tendons, cause de rupture-amorce de tumeurs. Presse médicale, 54, 869.

Kanavel, A. B. (1923): Tuberculous tenosynovitis of the hand: a report of fourteen cases. Surgery, Gynecology and Obstetrics, 37, 635.

McMaster, P. E. (1932): Late ruptures of extensor and flexor pollicis longus tendons following Colles fracture. Journal of Bone and Joint Surgery, 14, 93.

McMaster, P. E. (1933): Tendon and muscle ruptures: Clinical and experimental studies on the causes and location of subcutaneous ruptures. Journal of Bone and Joint Surgery, 15, 705.

Mason, M. L. (1930): Rupture of tendons of the hand. Surgery, Gynecology and Obstetrics, 50, 611. 